\title{
BMJ Open Combining transplant professional's psychosocial donor evaluation and donor self-report measures to optimise the prediction of HRQoL after kidney donation: an observational prospective multicentre study
}

\author{
Lieke Wirken (D) , ,2 Henriët van Middendorp, ${ }^{1,2}$ Christina W Hooghof, ${ }^{3}$ \\ Jan-Stephan Sanders, ${ }^{4}$ Ruth Dam, ${ }^{5}$ Karlijn A M I van der Pant, ${ }^{6}$ Judith Wierdsma, ${ }^{7}$ \\ Hiske Wellink, ${ }^{8}$ Philip Ulrichts, ${ }^{9}$ Andries J Hoitsma, ${ }^{3}$ Luuk B Hilbrands, ${ }^{3}$ \\ Andrea W Evers ${ }^{1,2}$
}

To cite: Wirken $L$, van Middendorp H, Hooghof CW, et al. Combining transplant professional's psychosocial donor evaluation and donor self-report measures to optimise the prediction of HRQoL after kidney donation: an observational prospective multicentre study. BMJ Open 2022;12:e045249. doi:10.1136/ bmjopen-2020-045249

- Prepublication history and additional supplemental material for this paper are available online. To view these files, please visit the journal online (http://dx.doi.org/10.1136/ bmjopen-2020-045249).

Received 20 0ctober 2020 Accepted 27 July 2021

Check for updates

(C) Author(s) (or their employer(s)) 2022. Re-use permitted under CC BY-NC. No commercial re-use. See rights and permissions. Published by BMJ.

For numbered affiliations see end of article.

Correspondence to

Dr Lieke Wirken;

I.wirken@fsw.leidenuniv.nl

\section{ABSTRACT}

Objectives Living donor kidney transplantation is currently the preferred treatment for patients with endstage renal disease. The psychosocial evaluation of kidney donor candidates relies mostly on the clinical viewpoint of transplant professionals because evidencebased guidelines for psychosocial donor eligibility are currently lacking. However, the accuracy of these clinical risk judgements and the potential added value of a systematic self-reported screening procedure are as yet unknown. The current study examined the effectiveness of the psychosocial evaluation by transplant professionals and the potential value of donor self-report measures in optimising the donor evaluation. Based on the stressvulnerability model, the predictive value of predonation, intradonation and postdonation factors to impaired longer term health-related quality of life (HRQLL) of kidney donors was studied.

Design An observational prospective multicentre study.

Setting Seven Dutch transplantation centres.

Participants 588 potential donors participated, of whom 361 donated. Complete prospective data of 230 donors were available. Also, 1048 risk estimation questionnaires were completed by healthcare professionals.

Methods Transplant professionals (nephrologists, coordinating nurses, social workers and psychologists) filled in risk estimation questionnaires on kidney donor candidates. Furthermore, 230 kidney donors completed questionnaires (eg, on HRQoL) before and 6 and 12 months after donation.

Primary and secondary outcome measures HRQoL, demographic and preoperative, intraoperative and postoperative health characteristics, perceived support, donor cognitions, recipient functioning and professionals risk estimation questionnaires.

Results On top of other predictors, such as the transplant professionals' risk assessments, donor self-report measures significantly predicted impaired longer term $\mathrm{HRQOL}$ after donation, particularly by poorer predonation

\section{STRENGTHS AND LIMITATIONS OF THIS STUDY}

$\Rightarrow$ This prospective study on optimising the psychosocial evaluation of kidney donors was conducted in seven Dutch transplantation centres and included both predonation and postdonation assessments of a large population of kidney donors.

$\Rightarrow$ The current study is the first assessing both donor self-report measures and transplant professional evaluations in the prediction of health-related quality of life (HRQoL) after donation.

$\Rightarrow$ Both donor demographic, medical and psychosocial factors and transplant recipient functioning were included as potential explanatory factors of $\mathrm{HRQOL}$ after donation.

$\Rightarrow$ The current study only included one predonation assessment at the start of the donor eligibility screening, while distress might be particularly high, and interventions useful, when surgery is actually planned.

physical (17\%-28\% explained variance) and psychological functioning (23\%).

Conclusions The current study endorses the effectiveness of the psychosocial donor evaluation by professionals and the additional value of donor self-report measures in optimising the psychosocial evaluation. Consequently, systematic screening of donors based on the most prominent risk factors provide ground for tailored interventions for donors at risk.

\section{INTRODUCTION}

Receiving a kidney from a living donor (living donor kidney transplantation) is currently the best treatment option for most patients with end-stage renal disease, as patients have better health-related quality of life (HRQoL) 
after transplantation than during dialysis treatment, and patient and graft survival rates are higher in comparison to receiving a kidney from a deceased donor. ${ }^{1-3}$ The recent increase in the number of living donor kidney transplantations has led to more research on donor well-being, including donor decision-making (eg, motivation, expectations and worries) and HRQoL. ${ }^{40}$ Previous research indicates that most donors recover well after surgery. However, a subgroup of donors experiences sustained HRQoL difficulties, ${ }^{59}$ potentially caused by donor or recipient complications, ${ }^{11-13}$ unmet donation expectations ${ }^{1415}$ or social-relational problems. ${ }^{16}$ An accurate psychosocial evaluation enables the early identification of problems and the provision of counselling to prevent donation-related difficulties. ${ }^{17}$ Currently, evidencebased guidelines for psychosocial eligibility screening are scarce, ${ }^{18}{ }^{19}$ because only little research is available on predictors for longer term HRQoL using predonation and intraoperative and postoperative measures. ${ }^{20-22}$ The most consistent risk factor of impaired HRQoL after donation has been poor predonation psychological functioning, ${ }^{9}$ whereas limited evidence has been found for a broad range of demographic, medical and psychosocial risk factors, including being single, donor complications and recipient functioning. ${ }^{72324}$ In the scarce amount of previous studies on predictors of longer term HRQoL after donation, assessments mostly took place at the time donors were admitted to the hospital and prepared for surgery. At this time, predonation interventions to prevent longer term HRQoL problems are not possible at the short term because of the upcoming surgery and recovery time afterwards. Therefore, in the current study, we would like to identify donors at risk for longer term HRQoL at an early stage of the donation procedure, to enable timely intervention before the actual donation would take place.

Because of the lack of large prospective prediction studies, the psychosocial donor evaluation relies mostly on the clinical viewpoint of transplant professionals. However, the accuracy of these clinical judgments during the donor screening and the potential added value of donor self-report measures around the time of screening are as yet unknown. Also, the currently used procedures to screen psychosocial donor eligibility are not consistent across donation programs. ${ }^{25}$ A standardised evidencebased psychosocial evaluation would facilitate tailored interventions for donors with a high-risk profile, but first more systematic knowledge about what constitutes the most important predictors of poor HRQoL after donation is necessary. Because the donor surgery can be viewed as a major stressor in a person's life, we used the stressvulnerability and resilience model as a basis for selection of potential risk and resilience factors. ${ }^{26}{ }^{27}$ In this model, next to demographic and medical factors, internal risk and resilience factors (such as predonation HRQoL and personality) interact with external stressors (eg, donor surgery) or protective factors (eg, social support) in determining the impact of stressful conditions.
The current prospective study aimed to examine the effectiveness of the psychosocial evaluation by transplant professionals and the potential value of donor self-report measures in predicting HRQoL at 6 and 12 months after donation, which may be used to optimise the psychosocial donor evaluation. Based on the limited previous prospective research in donors and data on the stressvulnerability and resilience model in other populations, we hypothesised that worse physical and mental HRQoL before donation as an internal risk factor, lower levels of social support as an external factor and more unrealistic expectations, more worries regarding the donation and a higher social sensitivity would be predictive donor factors for a lower physical and mental HRQoL 6 and 12 months after donation. Moreover, the predictive role of demographic (eg, age, gender, donation relationship), preoperative, intraoperative and postoperative health characteristics of the donor (eg, surgery complications, hospital stay) and the recipient (eg, pretransplantation treatment or post-transplantation graft failure or death during the first year after transplantation) and donor evaluations of pretransplant recipient-related functioning (eg, perceived health and impact on donor functioning) on short-term (6 months) and long-term (12 months) postdonation HRQoL were explored.

\section{MATERIALS AND METHODS Procedure}

All potential donors from seven Dutch transplantation centres (Radboud University Medical Center, University Medical Center Groningen, Leiden University Medical Center, Academic Medical Center Amsterdam, University Medical Center Utrecht, VU University Medical Center Amsterdam and Maastricht University Medical Center) were invited to participate in the study after their first screening visit (2011-2015). Directly after this first consultation, transplant professionals routinely involved in donor evaluation (nephrologists, coordinating nurses, social workers and psychologists) filled in a short questionnaire on their risk estimation for poorer donor HRQoL after donation. Also, potential donors completed a screening questionnaire either by email or on paper. If donation took place, donors received a similar postdonation questionnaire 6 and 12 months after surgery. Illiteracy was the only exclusion criterion.

\section{Participants}

\section{Transplant professionals}

On 533 potential donors (91\% of participating donors), 1048 risk estimation questionnaires were completed by coordinating nurses $(n=489)$, medical social workers $(n=339)$, nephrologists $(n=201)$ and psychologists $(n=19)$.

\section{Potential donors}

In total, 588 potential donors participated $(75 \%$ response rate), of whom $361(61 \%)$ actually donated a kidney. The mean time between screening and donation was 7.0 5 . 2 


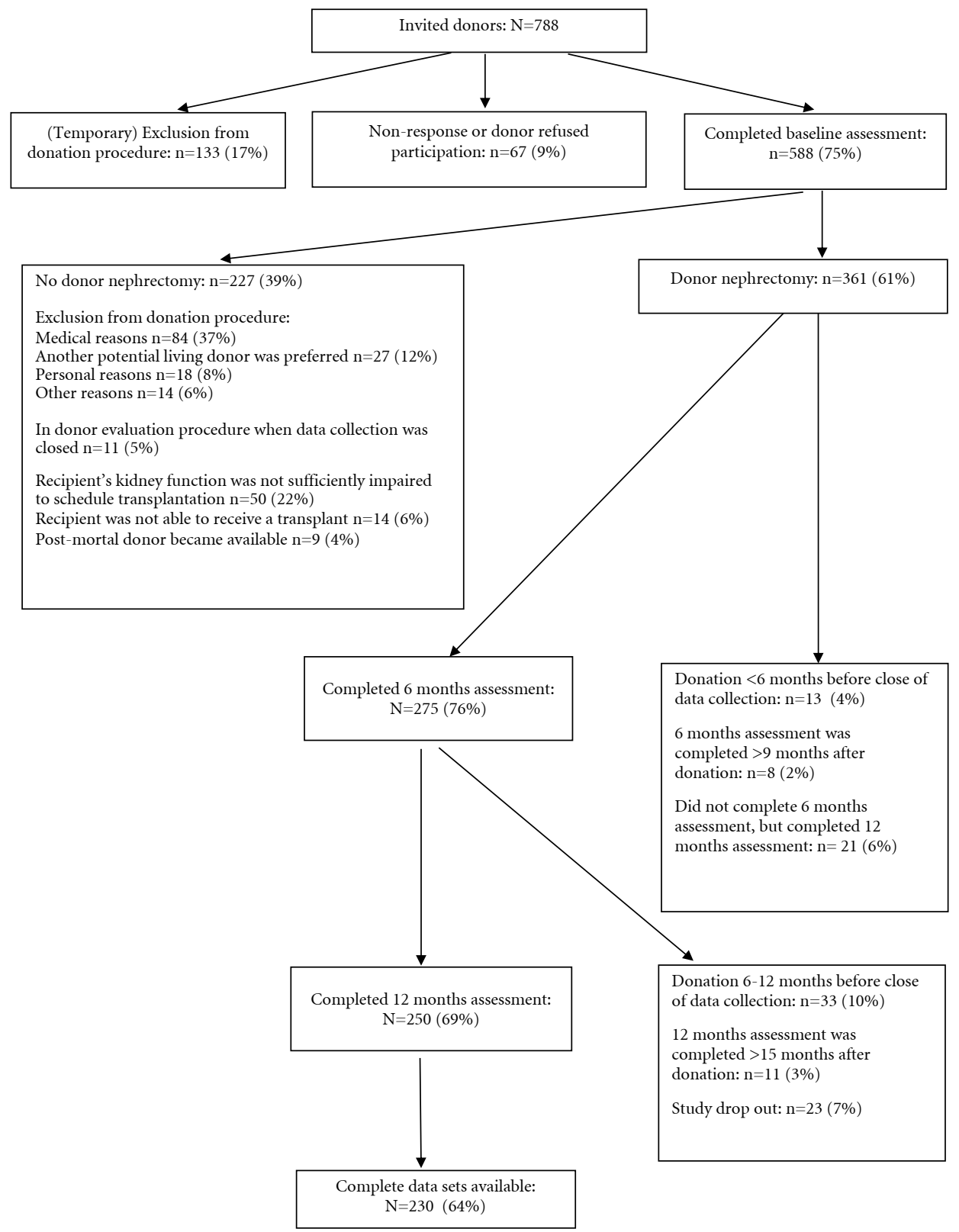

Figure 1 Study flowchart.

months (range 1-39 months). Reasons for exclusion from the donation procedure are presented in figure 1 . Complete data of 230 donors were available, excluding participants filling out the questionnaires more than 3 months after the intended time (figure 1).

\section{Measures}

Explanatory variables

Demographic and preoperative, intraoperative and postoperative health characteristics

Donor demographic characteristics as well as preoperative, intraoperative and postoperative health characteristics (eg, predonation physical comorbidity, hospital stay after donation, complications during the first year after donation) were assessed. Data on recipient's pretransplantation treatment and post-transplantation outcome (ie, graft failure or death during the first year after transplantation) were derived from the Dutch Organ Transplantation Registration system. ${ }^{28}$

\section{Risk estimations by transplant professionals}

Transplant professionals indicated their risk estimation of poorer longer term donor physical and psychosocial functioning on a 10-point scale; higher scores represented a higher risk of an unfavourable course. Physical risk estimations were represented in a single item. Psychosocial risk estimations were represented in a summary score based on (1) motivations, expectations and worries about donation (2) social support and recipient-related factors, (3) past and (4) current psychological functioning (Cronbach's alpha: 0.81) (electronic online supplemental material 1). Because risk estimations were not always 
completed by all four disciplines, an average risk estimation per donor was calculated; in secondary analyses, risk estimations of specific disciplines were explored (estimations of psychologists were excluded because of the small sample size).

\section{Predonation donor measures \\ HRQOL}

Physical functioning was assessed using the RAND Short Form-36 Health Status Inventory (RAND SF-36 ${ }^{29}$; and the Checklist Individual Strength (CIS)-Fatigue Scale Short Version. ${ }^{30}$

The RAND SF-36 is a 36-item questionnaire assessing eight HRQoL dimensions. Four dimensions measure physical health: Physical Functioning, Role Limitations due to Physical Health Problems, Pain and General Health Perceptions; summarised in the Physical Health Composite Score. The Hays norm-based scoring algorithm was applied, transforming raw scores into T-scores $(\mathrm{M}=50 \pm 10$ in the general population). Higher scores represent better HRQoL. ${ }^{29}$ Cronbach's alpha varied between 0.56 (General Health Perceptions) and 0.91 (Role Limitations due to Physical Health Problems).

The CIS short version (four items) assesses fatigue (eg, 'I feel tired'). Higher scores represent more fatigue. ${ }^{30}$ Cronbach's alpha was 0.80 .

\section{HRQoL}

Psychological functioning was assessed using four subscales of the RAND SF-36: Emotional Well-being, Role Limitations due to Emotional Problems, Social Functioning and Energy; summarised in the Mental Health Composite Score. ${ }^{29}$ Cronbach's alpha varied between 0.59 (Social Functioning) and 0.83 (Mental Health Composite).

Additionally, the NEO Personality Inventory-RevisedNeuroticism scale (eight items) assesses the neuroticism personality characteristic on a 5-point scale ('I Often feel helpless and want others to solve my problems') ${ }^{31}$ Higher scores represent higher sensitivity for stressful situations. Cronbach's alpha was 0.77 .

Perceived support was assessed using the Perceived Social Support scale (five items) of the Inventory for Social Reliance (ISR) (eg, 'When I am tense or under pressure, there is somebody to help me'). Scores are rated on a 4-point Likert scale. Higher scores represent lower perceived support. ${ }^{32}$ Cronbach's alpha was 0.86 .

Donor cognitions was assessed by the Donation Cognition Instrument $(\mathrm{DCI})^{10}$ and the Living Donation Expectancies Questionnaire (LDEQ). ${ }^{33}$

The DCI consists of two parts: Motivation and Expectations (DCI-ME; 22 items) and Worries (DCI-W; nine items). The DCI-ME assesses donor motivations and expectations, such as Donor Benefits ('I expect my own quality of life to improve as a result of the donation'); Recipient Benefits ('I wish to donate in order to improve the quality of life of the recipient'); Gratitude ('I expect the recipient to be very grateful for the donation') and
Idealistic Incentives ('I wish to make a contribution to a better world') on a 5-point scale. The DCI-W concerns worries about donation (eg, 'I am worried about the operation'), measured on a 4-point scale. Cronbach's alpha varied between 0.70 (Worries and Idealistic Incentives) and 0.78 (Donor Benefits and Recipient Benefits).

The LDEQ examines expectancies regarding donor's personal well-being (42 items), starting with 'As an organ donor, I expect...', measured on a 5-point scale. Six domains are distinguished: Interpersonal Benefits (eg, '...to be seen as heroic'); Personal Growth (eg, '...to feel proud of myself'); Spiritual Benefits (eg, '...to have a stronger religious faith'); Quid Pro Quo (eg, '...preferential treatment by the recipient after donation'); Health Consequences (eg, '...to experience a great deal of pain and discomfort') and Miscellaneous Consequences (eg, '...to have more financial problems'). Higher scores represent higher expectancies. ${ }^{33}$ Cronbach's alpha varied between 0.59 (Quid Pro Quo) and 0.82 (Personal Growth).

\section{HRQDL}

Social-relational functioning was measured using the Interpersonal Sensitivity Measure (IPSM) ${ }^{34}$ and the ISR. ${ }^{32}$

Of the IPSM, the subscales Interpersonal Awareness (seven items; for example, 'I worry about the effect I have on other people') and Timidity (eight items; for example, I will do something I do not want to do rather than offend or upset someone') were assessed on a four-point scale. Higher scores represent greater interpersonal awareness or timidity. ${ }^{34}$ Cronbach's alphas were 0.79 (Interpersonal Awareness) and 0.56 (Timidity).

\section{Recipient functioning}

Donor perspectives on the donor-recipient relationship quality, current physical and emotional recipient functioning and the influence of recipient's kidney disease on the donor's life were assessed using 10-point scales (eg, 'To what extent is your life influenced by the recipients' kidney disease?').

\section{Postdonation outcome measures}

Physical and psychological HRQoL 6 and 12 months postdonation were the outcome measures, assessed by the RAND SF-36 Physical and Mental Health Composite Scores. ${ }^{29}$

\section{Statistical analyses}

Normal distribution of all variables was verified; in case of skewed or kurtosed variables, logarithmic or reflected transformations were applied in order to enable parametric statistics. First, the association of donor demographic characteristics, preoperative, intraoperative and postoperative donor and recipient health status, transplant professionals' risk estimations and predonation donor measures with HRQoL at 6 and 12 months postdonation was examined using Pearson correlations. Positive correlations indicate that higher values on the 
explanatory variables were related to better postdonation HRQoL.

To examine the relative contribution of potential explanatory variables, all variables that showed significant correlations to HRQoL at 6 or 12 months postdonation were included in hierarchical multiple linear regression analyses for that outcome. To study the specific role of transplant professionals' judgements of donor risk and donor measures in predicting postdonation HRQoL, the hierarchical multiple linear regression analyses were conducted with donor demographic characteristics and preoperative, intraoperative and postoperative donor and recipient health status (block 1) and either transplant professionals' risk estimations or donor self-report measures (block 2) as explanatory variables of physical or psychological HRQoL 6 or 12 months postdonation. If predonation physical or psychological HRQoL was a significant explanatory variable, subsequent analyses were conducted to examine whether specific HRQoL aspects predicted the outcome.

In order to examine the relative contribution of transplant professionals' risk estimations and donor measures in predicting physical or psychological HRQoL 6 or 12 months postdonation, the hierarchical multiple linear regression analyses described above were repeated with either transplant professionals' risk judgements or the donor self-report measures being added as explanatory variables in block 3 of the model, depending on which category was entered in the second block.

A p value below 0.05 was considered significant, but explanatory variables with a $\mathrm{p}$ value up to 0.10 were also reported in the tables. Data were analysed using IBM SPSS software V.22. ${ }^{35}$

\section{Patient and public involvement}

This study was initiated based on the clinical question from healthcare professionals on how to identify donors at risk for impaired functioning after donation. The research questions and outcome measures were thus based on the clinical expertise of the healthcare professionals who are specialised in donor care, including coordinating nurses and medical social workers. Before the start of this prospective multicenter study, a pilot study in a small group of donors was conducted to identify potential explanatory variables of worse HRQoL after donation which had to be included in the final prospective study. The study results have been and will be disseminated to the donors and healthcare professionals involved in donor care by means of presentations at patient associations and professional conferences.

\section{RESULTS}

\section{Donor characteristics}

Demographic characteristics and preoperative, intraoperative and postoperative health status of 230 included donors are reported in table 1 . There was an almost equal gender representation ( $59 \%$ women), with a mean
Table 1 Demographic characteristics and preoperative, intraoperative and postoperative health status of donors $(\mathrm{N}=230)$

\begin{tabular}{|c|c|}
\hline Characteristic & Descriptives \\
\hline \multicolumn{2}{|l|}{ Donor predonation characteristics } \\
\hline Age mean $\pm S D$ (range) years & $\begin{array}{l}55.1 \pm 10.7(23-76) \\
\text { years }\end{array}$ \\
\hline \multicolumn{2}{|l|}{ Gender } \\
\hline Female & $59 \%$ \\
\hline Male & $41 \%$ \\
\hline \multicolumn{2}{|l|}{ Marital status* } \\
\hline Single & $19 \%$ \\
\hline Steady partner & $81 \%$ \\
\hline \multicolumn{2}{|l|}{ Educational level† } \\
\hline Primary education & $5 \%$ \\
\hline Secondary education & $62 \%$ \\
\hline \multicolumn{2}{|c|}{$\begin{array}{l}\text { Tertiary education (higher vocational/ 33\% } \\
\text { university) }\end{array}$} \\
\hline \multicolumn{2}{|l|}{ Donation type } \\
\hline Direct & $83 \%$ \\
\hline Kidney exchange procedure & $8 \%$ \\
\hline Anonymous & $9 \%$ \\
\hline \multicolumn{2}{|l|}{ Donor-recipient relationship } \\
\hline Spouse & $30 \%$ \\
\hline Parent & $20 \%$ \\
\hline Sibling & $18 \%$ \\
\hline Child & $3 \%$ \\
\hline Other-related (eg, uncle) & $17 \%$ \\
\hline Other-unrelated (eg, friend) & $3 \%$ \\
\hline Anonymous & $9 \%$ \\
\hline \multicolumn{2}{|l|}{ Religious affiliation $†$} \\
\hline Religious & $53 \%$ \\
\hline Non-religious & $47 \%$ \\
\hline \multicolumn{2}{|l|}{ Donor health status } \\
\hline \multicolumn{2}{|l|}{ Surgery type } \\
\hline Mini-incision donor nephrectomy & $15 \%$ \\
\hline Laparoscopy & $85 \%$ \\
\hline Hospital stay (days) & $\begin{array}{l}4.57 \pm 1.6 \text { (range } \\
1-14 \text { ) days }\end{array}$ \\
\hline \multicolumn{2}{|l|}{ Donor complicationsł } \\
\hline No complications & $85 \%$ \\
\hline Grade I & $8 \%$ \\
\hline Grade II & $6 \%$ \\
\hline Grade III a & - \\
\hline Grade III b & $1 \%$ \\
\hline Grade IV a & - \\
\hline Grade IV b & - \\
\hline Grade V & - \\
\hline
\end{tabular}

Continued 


\begin{tabular}{|c|c|}
\hline Characteristic & Descriptives \\
\hline \multicolumn{2}{|c|}{ Recipient complications } \\
\hline \multicolumn{2}{|l|}{ Graft failure } \\
\hline Yes & $6 \%$ \\
\hline No & $94 \%$ \\
\hline \multicolumn{2}{|l|}{ Patient death } \\
\hline Yes & $3 \%$ \\
\hline No & $97 \%$ \\
\hline \multicolumn{2}{|c|}{$\begin{array}{l}{ }^{*} \mathrm{n}=228 . \\
\dagger \mathrm{n}=229 . \\
\text { †Categorisation according the Clavien-Dindo classification system } \\
\text { (Dindo et al 2004). }{ }^{36}\end{array}$} \\
\hline
\end{tabular}

age of 55.1 ( $\mathrm{SD}=10.7$; range $23-76)$ years, and mostly a secondary level education (62\%). The majority $(83 \%)$ donated directly to a recipient they knew. Donors stayed on average 5 days in the hospital, with 35 donors $(15 \%)$ experiencing complications of either grade I: no need for therapeutic interventions $(n=19 ; 8 \%)$, grade II: surgical, endoscopic or radiological intervention required $(n=14$; $6 \%$ ) or grade III-b: surgical, endoscopic or radiological intervention required under general anaesthesia $(n=2$; $1 \%) .{ }^{36}$ In recipients, 11 (5\%) kidneys were rejected and 6 $(3 \%)$ recipients died after kidney transplantation. There were no major donor complications; none of the donors died or had to receive dialysis treatment during the data collection period.

\section{HRQOL outcomes}

Donor physical HRQol at 6 months was $M=54.9 \pm 7.0$ (range 22-61) and at 12 months $M=55.5 \pm 6.6$ (range 22-61). Donor psychological HRQoL at 6 months was $M=53.4 \pm 8.6$ (range 25-66) and at 12 months $M=54.6 \pm 8.5$ (range 22-66). ${ }^{37}$

\section{Explanatory variables of poorer longer term HRQoL}

Physical HRQoL 6 and 12 months after donation

Poorer physical HRQoL after donation was related to higher transplant professionals' physical risk judgements as well as multiple donor self-report factors (see table 2).

\section{Demographic and preoperative, intraoperative and postoperative} health status

Demographic characteristics and health status explained only $3 \%$ and $6 \%$ of variance of physical HRQoL 6 and 12 months postdonation, respectively, with no individual variables being consistent explanatory variables.

\section{Transplant professionals' risk estimations}

A higher transplant professionals' risk estimation of a donor's physical functioning was associated with poorer physical HRQoL at $6(\beta=-0.21, p=.01 ; F(6,170)=1.98$, $p=.07)$ and 12 months postdonation $(\beta=-0.27, p<.001$; $F(6,170)=4.05, p=.001)$, adding a non-significant $4 \%$ and a significant $7 \%$ of the explained variance, respectively.
Regarding specific disciplines, at 6 months after donation, higher risk estimations of coordinating nurses $(\beta=-0.22$, $p=.02)$ and medical social workers $(\beta=-0.27, p=.003)$ predicted worse physical HRQoL, and at 12 months all disciplines $(-0.20 \leq \beta \leq-0.31,0.04 \leq p \leq .001)$.

\section{Donor measures}

Significant explanatory variables of poorer physical HRQoL 6 months postdonation were a lower predonation physical HRQoL $(\beta=0.44, p<.001)$ and donor estimations of more recipient limitations in daily life $(\beta=0.17$, $p=0.01)$, adding $33 \%$ to the total explained variance $F(12,166)=0.48, p<.001$. For poorer physical HRQoL 12 months postdonation, a lower predonation physical HRQoL $(\beta=0.37, \beta<.001)$ remained a significant explanatory variable, adding a variance of $22 \%, F(12,166)=5.38$, $p<.001$. Looking into the specific aspects of physical HRQoL, the general health perception subscale was the only significant explanatory variable at both $6(\beta=0.21$, $p=.02)$ and 12 months $(\beta=0.19, p=.03)$ after donation.

\section{Psychological HRQoL 6 and 12 months after donation}

Poorer postdonation psychological HRQoL was related to higher transplant professionals' psychological risk estimations as well as various categories in the donor measures (table 3).

\section{Demographic characteristics and preoperative, intraoperative and postoperative health status}

Demographic characteristics and health status explained $21 \%$ and $22 \%$ of the variance of psychological HRQoL 6 and 12 months postdonation, respectively. The only consistent explanatory variable was having a child-parent donor-recipient relationship, which was a protective factor for poorer psychological HRQoL 12 months after donation (in transplant professionals model: $\beta=-.23$, $\mathrm{p}=0.002$; in donor measures model: $\beta=-0.19, \mathrm{p}=0.02$ ) .

\section{Transplant professionals' risk estimations}

A higher risk estimation by transplant professionals regarding donor's psychosocial functioning added $2 \%$ and $1 \%$ of the variance to the prediction of poorer psychological HRQoL at six (despite the separate predictor not reaching significance: $\beta=-0.15, p=0.053 ; F(18,160)=2.71$, $p<0.001)$ and 12 months after donation $(\beta=0.17, p=0.03$; $F(18,160)=2.61, p=0.001)$. Higher risk estimations of medical social workers (6 months: $\beta=-0.21, p=0.02 ; 12$ months: $\beta=-0.20, p=0.03$ ) significantly predicted worse psychological HRQoL after donation.

\section{Donor measures}

Of donor measures, poorer predonation psychological HRQoL was the only significant explanatory variable of poorer psychological HRQoL 6 ( $\beta=0.26, p=0.02$; $\mathrm{F}(32,120)=3.15, \quad p<0.001)$ and 12 months postdonation $(\beta=0.31, p=0.01 ; \mathrm{F}(32,120)=3.08, p<0.001)$, adding $25 \%$ and $23 \%$ explained variance. Looking into the specific aspects of psychological HRQoL, poorer emotional wellbeing was the only significant explanatory variable at 


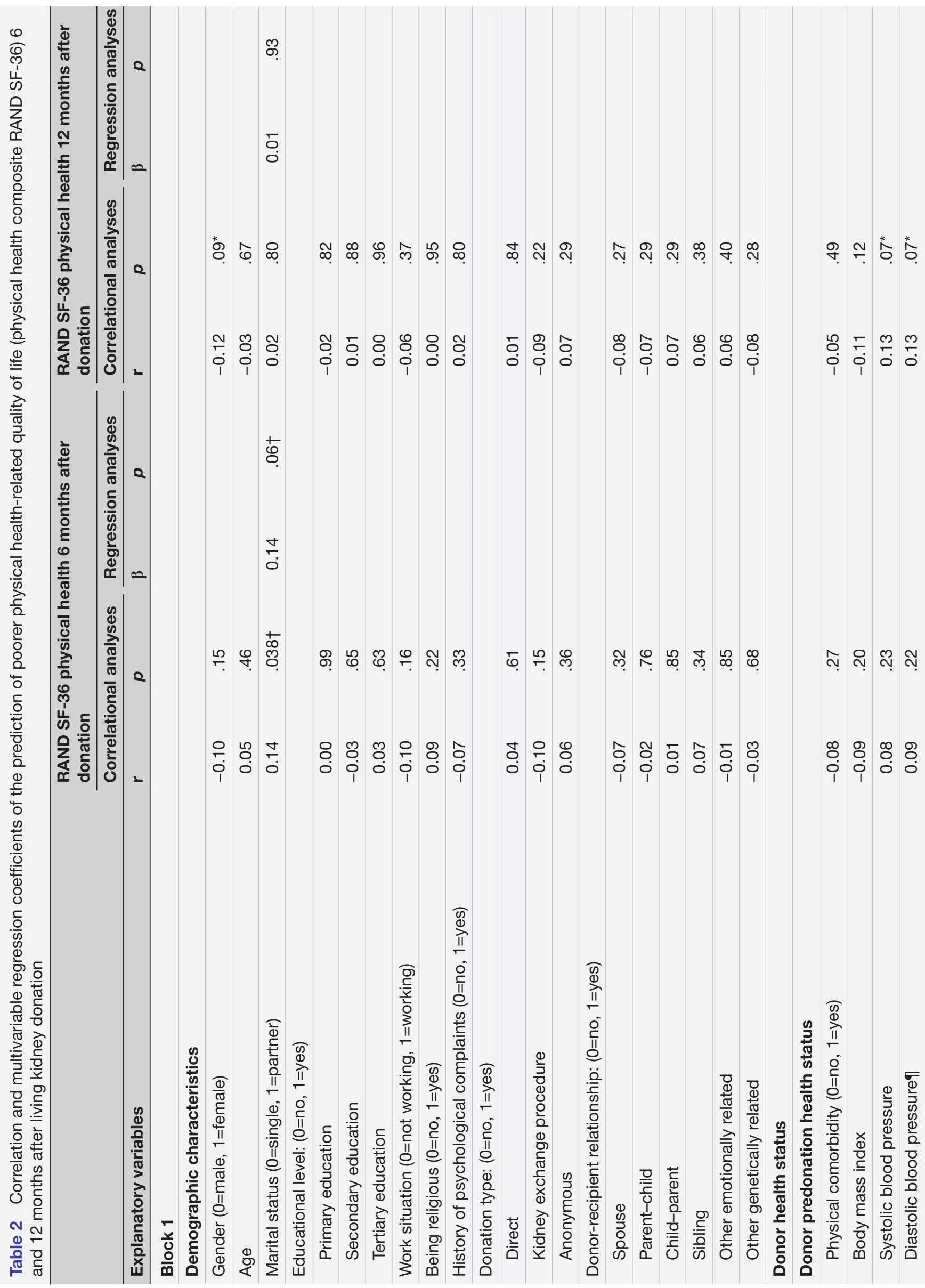




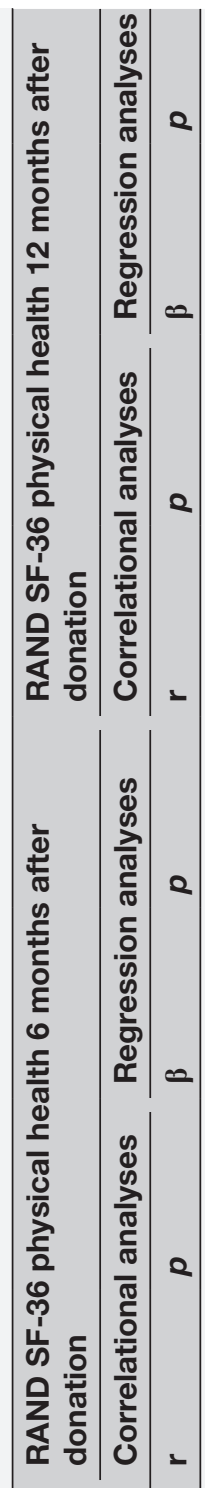

ㅇํ 누 웅ํำ

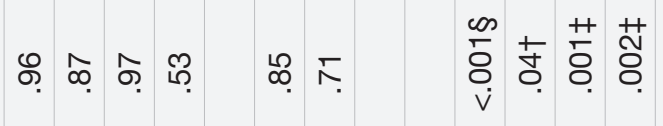

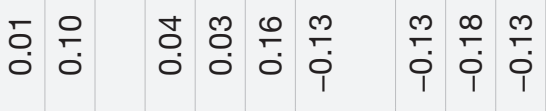

$\begin{array}{lllllll}8 & 0 & 8 & 1 & 0 & 5 & 9 \\ 0 & 0 & 0 & 0 & 0 & 0\end{array}$

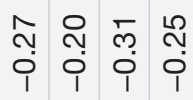

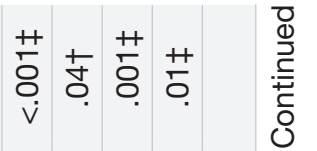

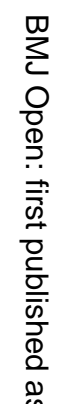

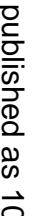

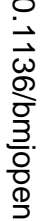

茂

+艹

లె

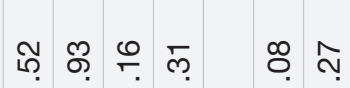

宽下 下

$\begin{array}{lllllllll}\hat{1} & 0 & 0 & 0 & 0 & 0 & 0 & 0 & 0 \\ 0 & 0 & 0 & 0 & 0 & 0 & 0 & 0 & 0 \\ 0\end{array}$

$\begin{array}{llllll}\stackrel{0}{0} & 5 & 0 & 0 & 0 & 0 \\ 0 & 0 & 0 & 0 \\ 0 & 0 & 0 & 0 \\ 0 & 0 & 0\end{array}$

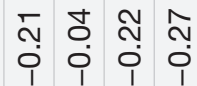

(1)

芯

वृ

产 


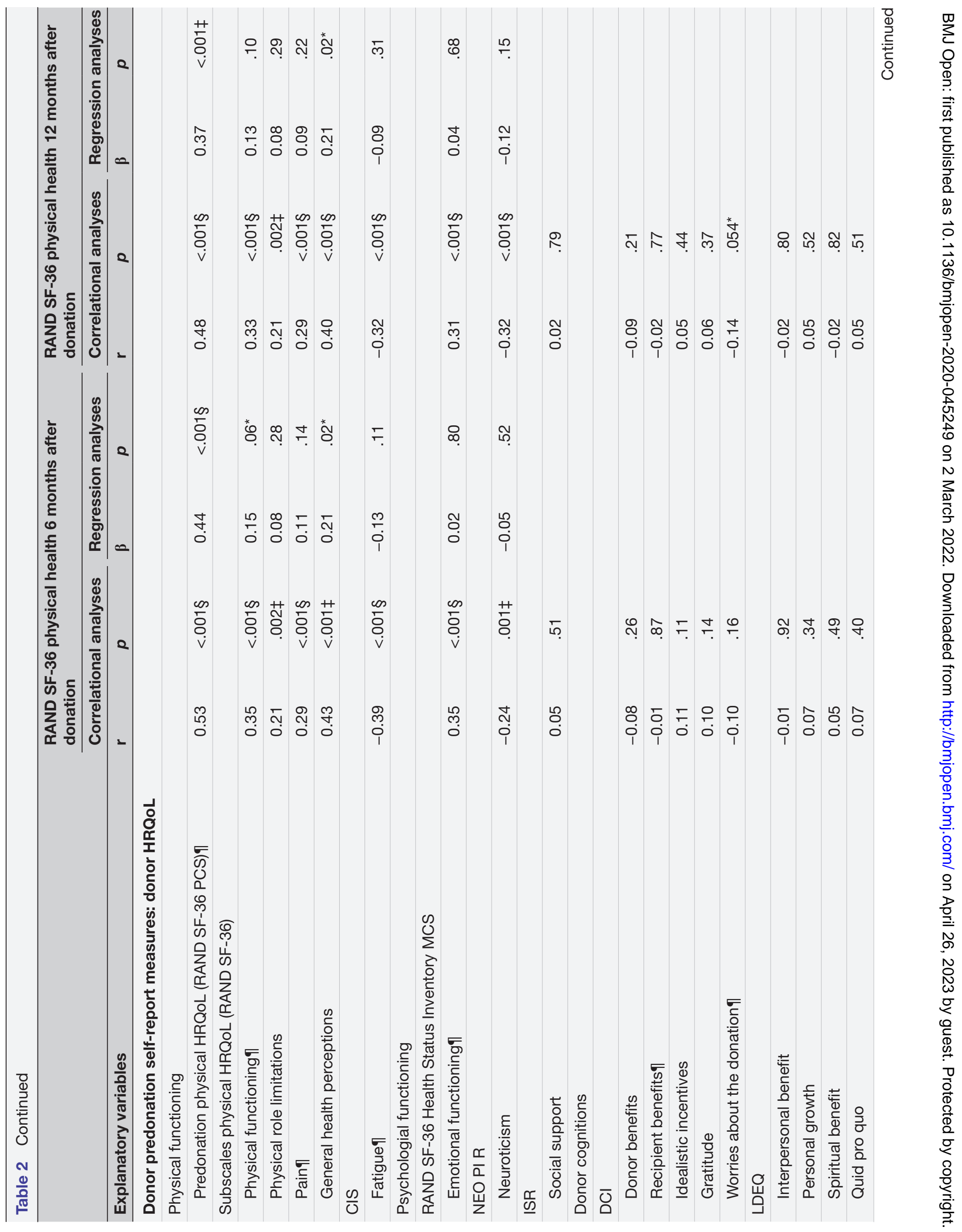




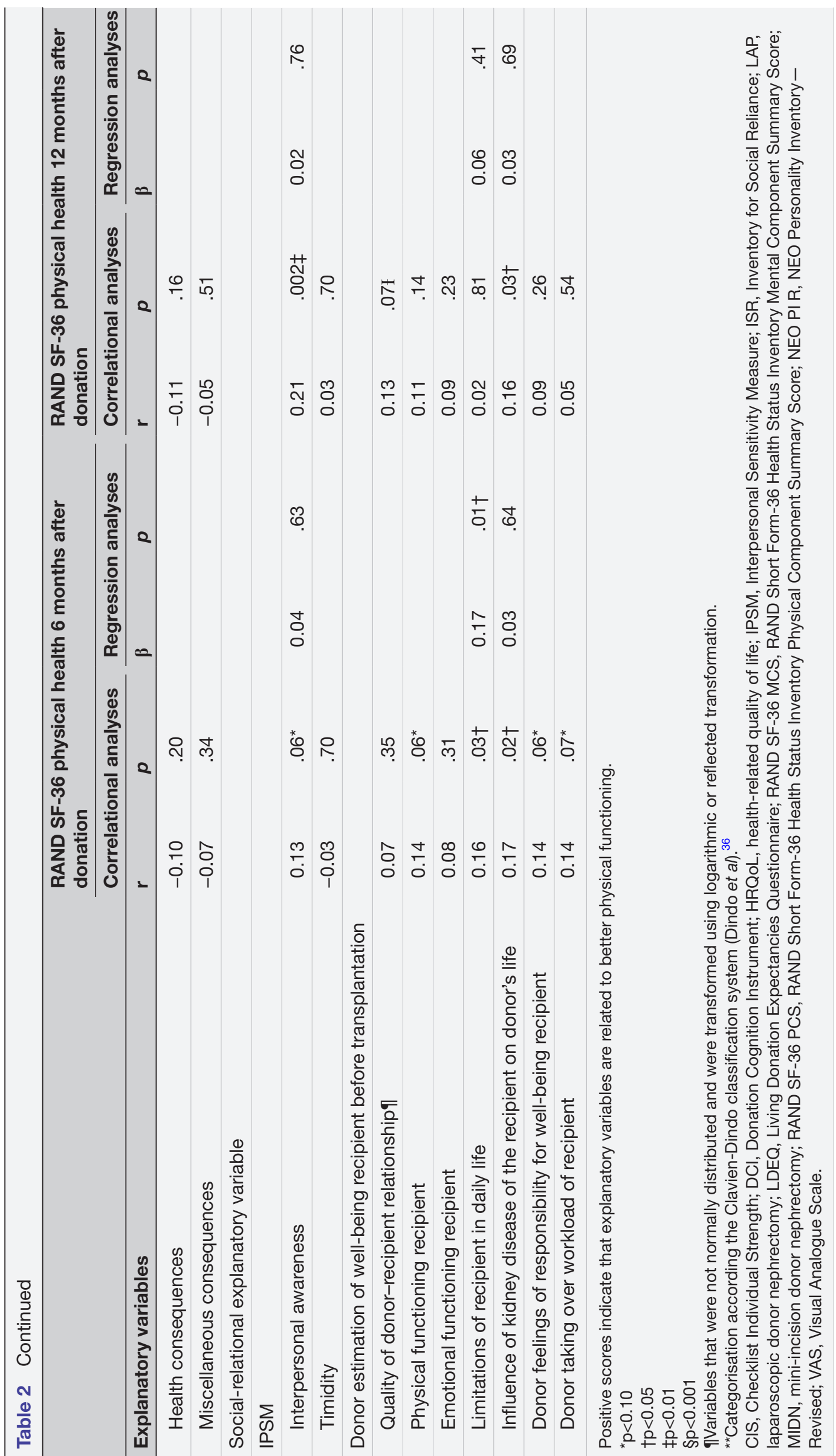

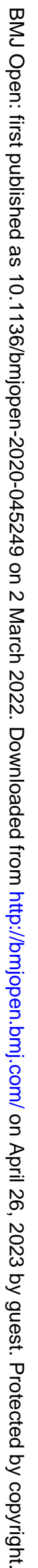




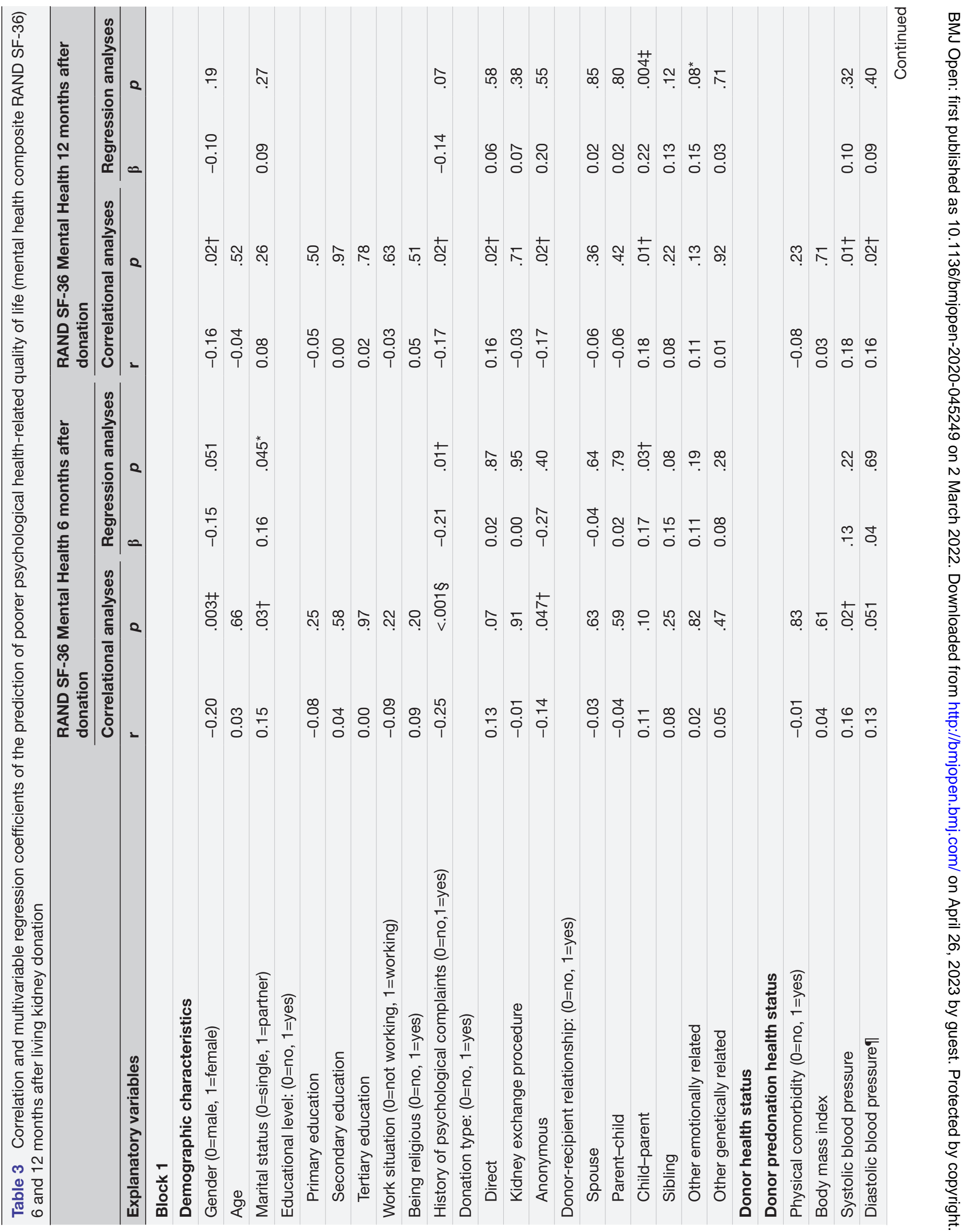




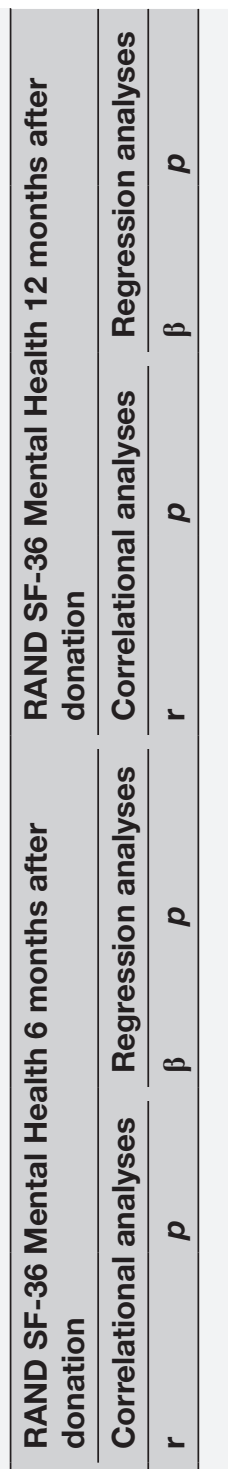

$$
\begin{aligned}
& \stackrel{\oplus}{\text { ஸ̣ }} \stackrel{0}{\leftarrow} ?
\end{aligned}
$$

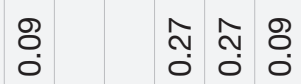$$
\text { ஸุ }
$$

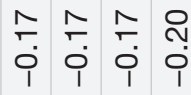

Lั

$\infty$ ๙.

苂

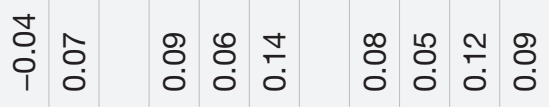

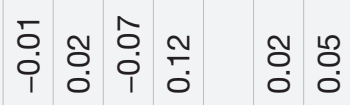

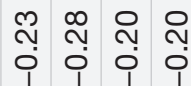

ก.

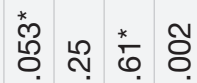

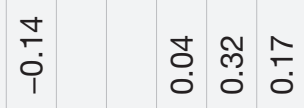

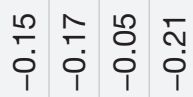

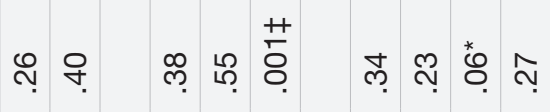

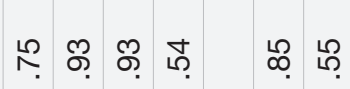

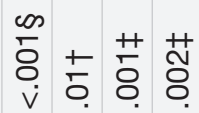

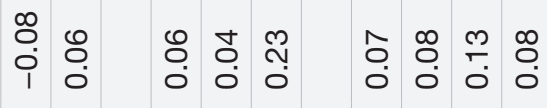

$\begin{array}{llllllll}1 & 0 & 0 & 0 & 0 & 0 & 0 \\ 0 & 0 & 0 & 0 & 0\end{array}$

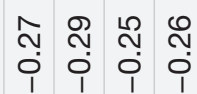
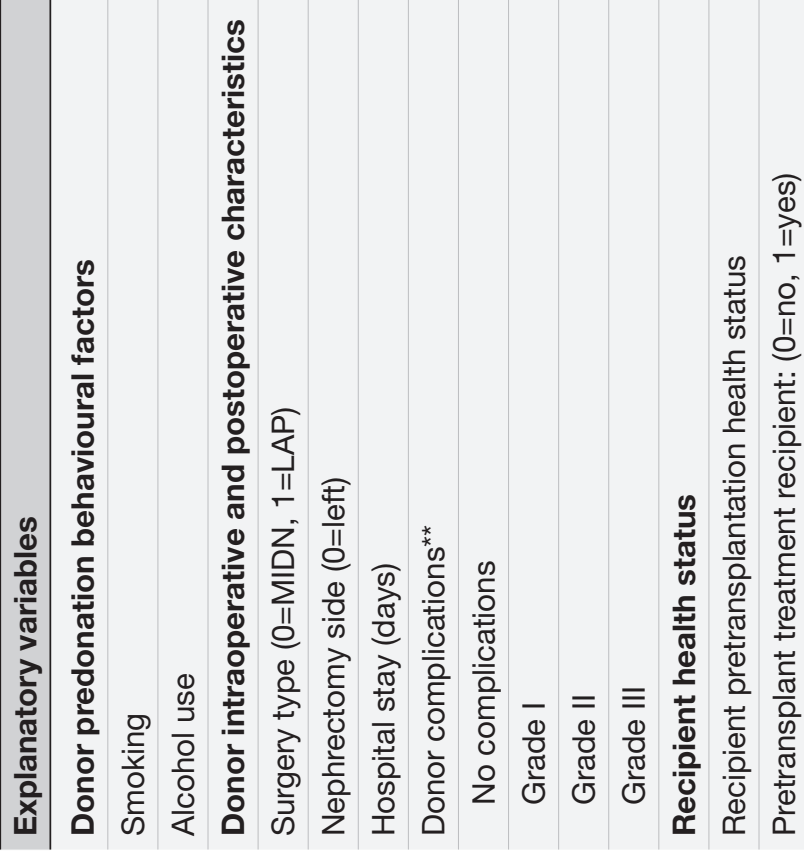


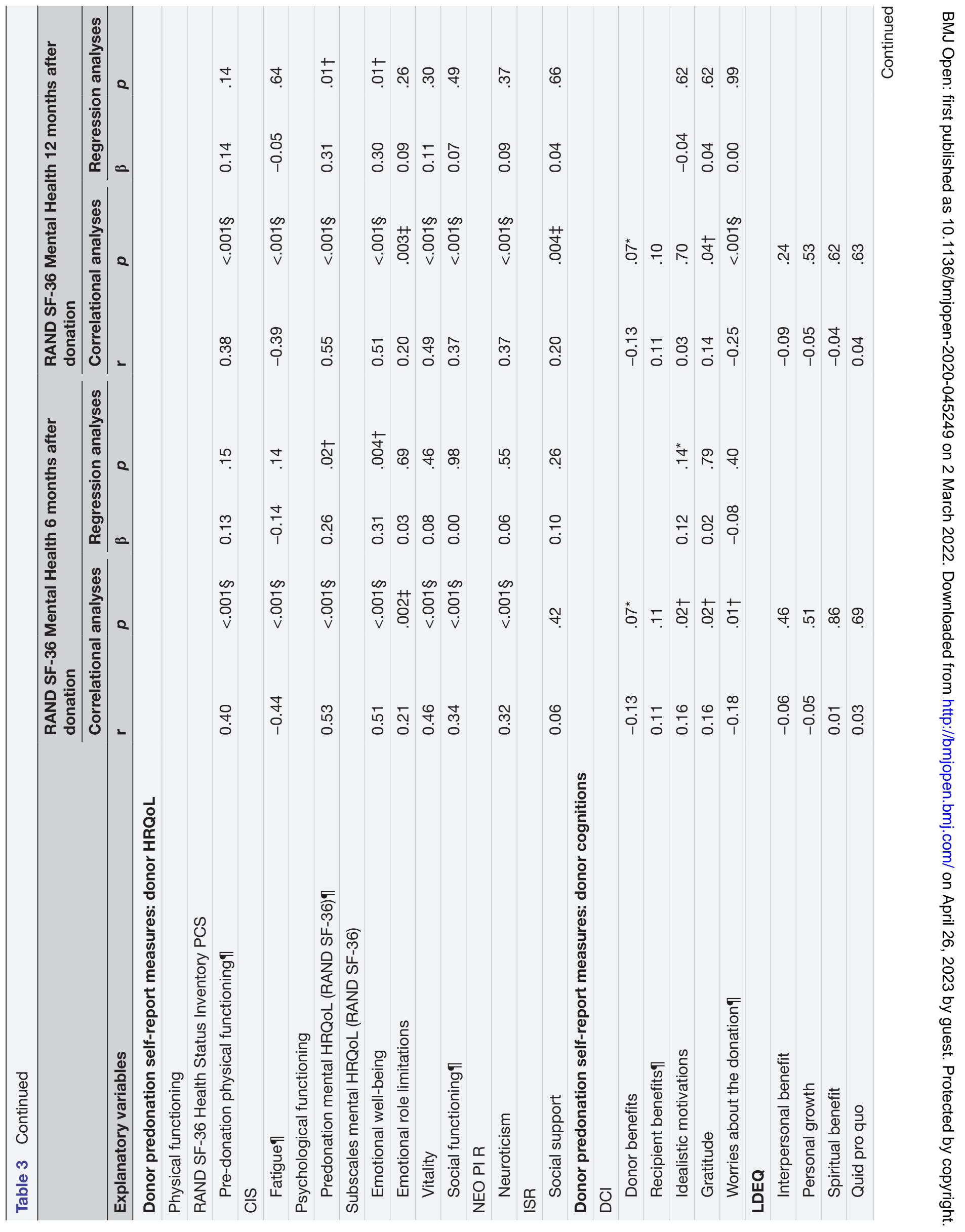




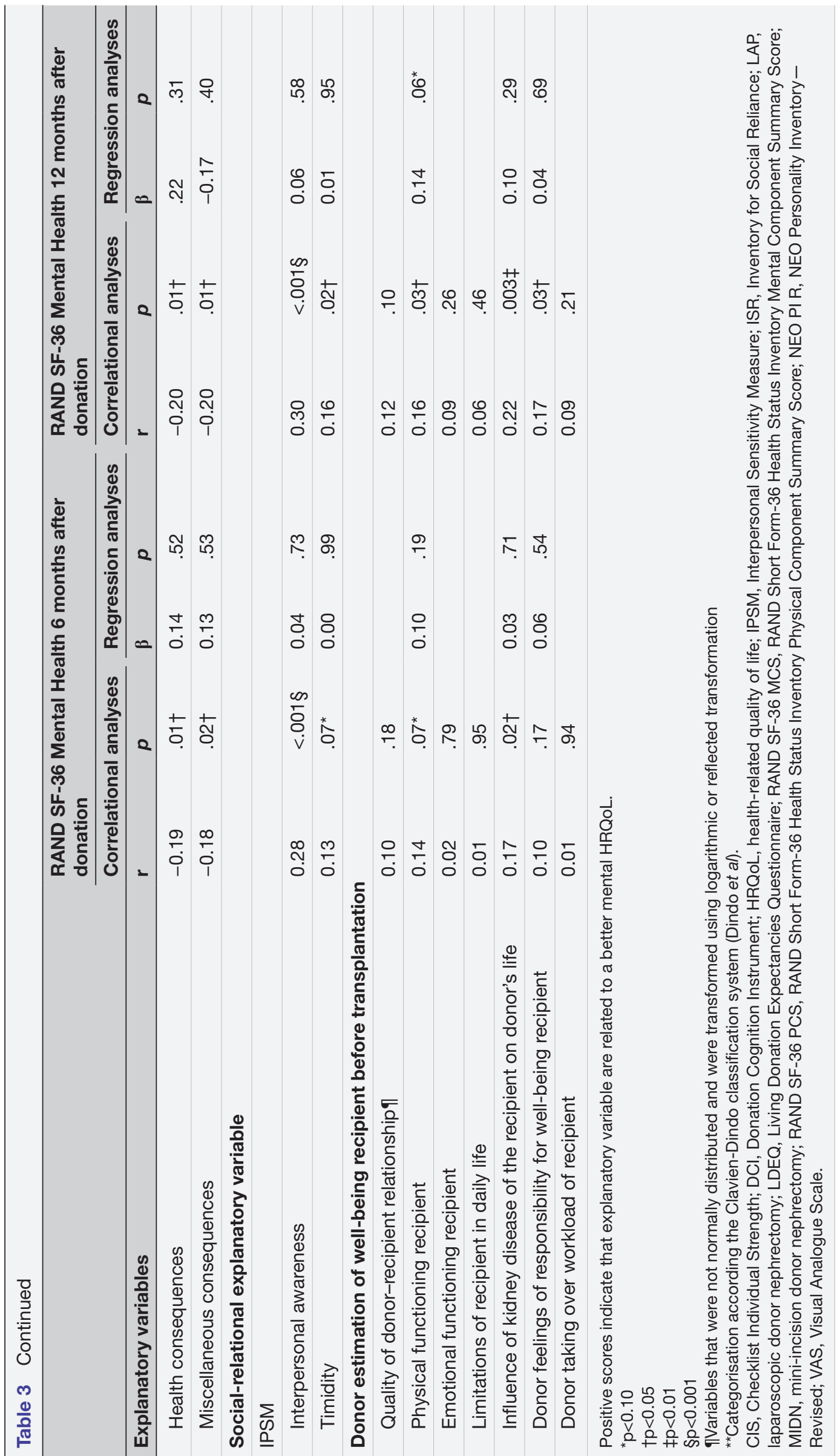

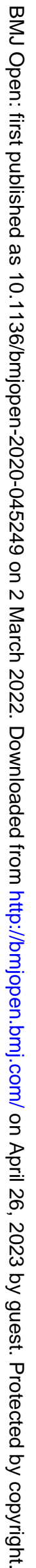




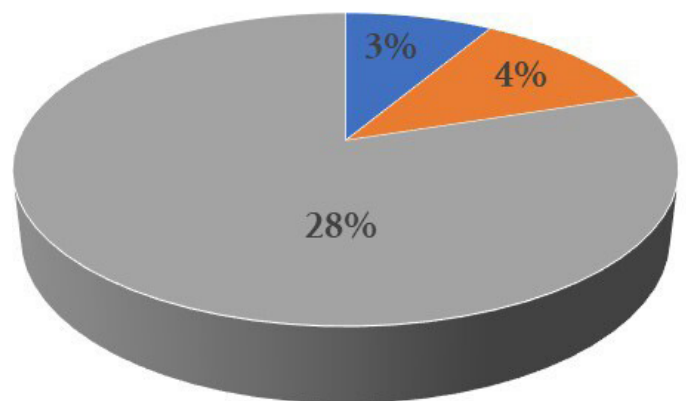

6 months

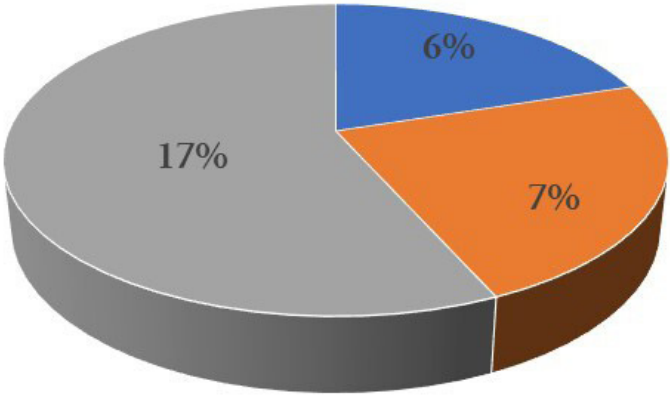

12 months

- demographic and medical factors

- transplant professionals' risk estimations

" donor self-report measures

Figure 2 Relative contribution of donor demographic/medical factors, transplant professionals' risk estimations, and donor self-report measures on the explained variance of physical functioning 6 and 12 months after donation.

both $6(\beta=0.31, p=0.004)$ and $12(\beta=0.30, p=0.01)$ months postdonation.

\section{Relative contribution of transplant professionals' risk estimations and donor measures}

Both transplant professionals' risk estimations and donor measures added significant variance to the prediction of physical and psychological HRQoL on top of demographic variables and health status. The additional value of transplant professionals' risk estimations on top of donor measures was limited in predicting both physical $(0 \%-2 \%)$ and psychological HRQoL $(0 \%-1 \%)$, while using donor measures added $17 \%-28 \%$ of explained variance in physical and 23\% in psychological HRQoL on top of transplant professionals' risk estimations (see figures 2 and 3 ).

To rule out the influence of potential bias by specific dropout, analyses of donors with complete assessments were repeated in donors completing only the $6(n=275)$ or $12(\mathrm{n}=250)$ month assessment. This led to very similar results (correlations $>0.97$ with predicted values).

\section{DISCUSSION}

Currently, the psychosocial donor evaluation is mainly based on clinical judgements of transplant professionals. An evidence-based evaluation would enable transparent eligibility decisions and interventions for donors with a high-risk profile. This study examined the effectiveness of the current psychosocial donor evaluation by transplant professionals and the potential improvement of the evaluation using donor self-report measures. Based on the stressvulnerability model, different psychosocial factors were included as potential explanatory variables of HRQoL at 6 and 12 months after donation, including potential internal, external and intermediate cognitive-behavioural risk factors. Results showed that both transplant professionals' risk judgements and donor self-report measures

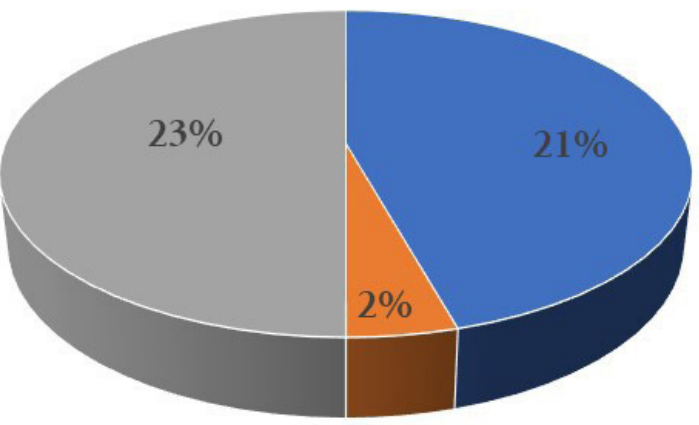

6 months

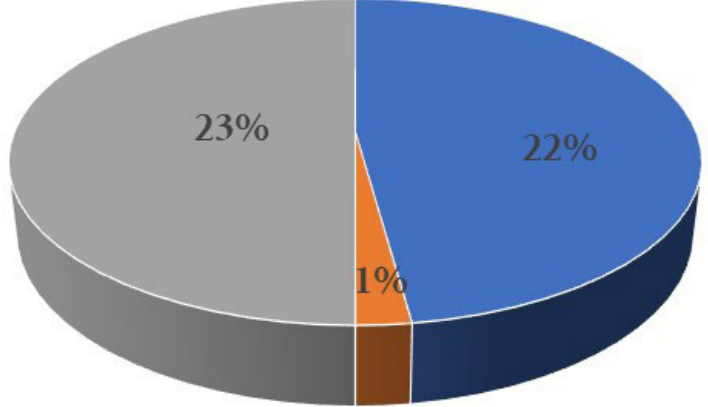

12 months

- demographic and medical factors

- transplant professionals' risk estimations

- donor self-report measures

Figure 3 Relative contribution of donor demographic/medical factors, transplant professionals' risk estimations and donor self-report measures on the explained variance of psychological functioning 6 and 12 months after donation. 
predicted longer term donor HRQoL, with an emphasis on the role of internal vulnerability factors (predonation HRQoL). These findings endorse the value of the current evaluation by professionals and stress the importance of using donor self-report measures to improve the predictive value of professionals' risk assessments.

The finding that donor self-report measures optimise transplant professionals' eligibility screening confirms and extends previous research in patient samples, indicating that patient-reported outcomes (PROs) can improve the quality of clinical decision-making and efficiency of consultations. ${ }^{38} 39$ In addition, self-report questionnaires could provide (potential) donors insight into donation decision-making and evaluate the donation experience. Nevertheless, donor self-report measures could not replace professionals' risk assessments, because of the potential influence of socially desirable responses due to an often strong desire for donation. ${ }^{4041}$

In line with previous studies, the internal factor of predonation HRQoL levels was shown to best predict postdonation HRQoL in the current study. ${ }^{42}{ }^{43}$ Possibly, the other variables (eg, predonation cognitions) contribute indirectly to postdonation HRQoL through their association with predonation HRQoL. Impaired longer term donor physical functioning was predicted by higher risk estimations of all transplant professionals, while only medical social workers predicted longer term psychological functioning. This could indicate that donors prefer to share psychosocial problems with social workers, but it could also reveal potential time constraints to discuss psychosocial issues during consultations.

Based on the current study, evidence-based criteria could be added to donor-screening guidelines. In order to examine the potential role of an encompassing number of PROs based on the different facets of the stressvulnerability model, a large amount of questionnaires was used in the current study. However, based on the results, in clinical practice screening could be conducted in a stepwise fashion, using a short-screening questionnaire to obtain an indication of HRQoL before starting the donor evaluation (eg, the RAND SF-36, which takes about $10 \mathrm{~min}$ to complete). These results could be integrated into eligibility screening consultations with transplant professionals, to increase awareness or clarification of possible problems in potential donors. If a risk profile (lowered HRQoL) is found, additional assessments could identify specific donation-related risk or resilience factors (eg, external factors such as social support and intermediate factors such as unrealistic cognitions and worries) to offer tailored interventions.

This study provides good indications of the most important factors in donor eligibility screening. Nonetheless, the results may have been influenced by a number of factors. The $75 \%$ response rate might limit generalisability of the findings to the total donor population. However, the selection bias is probably limited because the most prominent reason for non-participation was exclusion from the donation procedure by professionals
$(17 \%)$. Also, the screening questionnaire was completed at the beginning of the donor evaluation, in order to prevent the exclusion of donors later on in the trajectory and provide support to high-risk donors. At this time, the motivation to donate dominates and probably fewer worries about the surgery are experienced in comparison with the weeks before surgery. Consequently, an additional donor self-report screening could be useful when surgery is planned, to provide interventions for donors experiencing distress. Also, there was a large variability in time ( $M=7$ months) between screening and donation, which could be representative for the kidney donor population.

The Dutch healthcare setting of kidney donors cannot automatically be generalised to other healthcare settings in terms of access to care and regulations for health insurance, which are well organised and available to all inhabitants of The Netherlands. Future studies should examine this generalisation of findings. Finally, although we aimed to include an encompassing set of explanatory variables, there might be other explanatory variable of postdonation HRQoL of kidney donors, such as economic concerns about donation. Future research should include these potential predictors (eg, ambivalence and coercion) and validate those that were identified in the current study. ${ }^{44}$ Finally, even if relevant predonation explanatory factors are identified, it is still not possible to provide a perfect or complete prediction of postdonation HRQoL. For instance, because unpredictable life events could occur after donor screening, such as graft rejection after transplantation, which could influence donor outcomes after donation. Therefore, flexibility in donor follow-up is warranted. Future research would be needed to determine whether these predictors might also be useful to base eligibility decisions on.

In conclusion, the psychosocial donor evaluation conducted by professionals is effective in predicting longer term donor HRQoL. Donor self-report measures, with particularly poorer predonation physical and psychological functioning, could optimise the psychosocial evaluation of professionals. This can improve reliable donor eligibility decisions and tailored interventions for highrisk donors.

\section{Author affiliations}

${ }^{1}$ Health, Medical and Neuropsychology Unit, Leiden University, Leiden, The Netherlands

${ }^{2}$ Department of Medical Psychology, Radboudumc, Nijmegen, The Netherlands ${ }^{3}$ Department of Nephrology, Radboudumc, Nijmegen, The Netherlands

${ }^{4}$ Division of Nephrology, Department of Internal Medicine, University Medical Center Groningen, Groningen, The Netherlands

${ }^{5}$ Department of Nephrology, Leiden University Medical Center, Leiden, The Netherlands

${ }^{6}$ Department of Internal Medicine/Nephrology, Renal Transplant Unit, Amsterdam UMC, Amsterdam, The Netherlands

${ }^{7}$ Department of Nephrology, University Medical Center Utrecht, Utrecht, The Netherlands

${ }^{8}$ Department of Nephrology, Amsterdam UMC VUMC Site, Amsterdam, The Netherlands 
${ }^{9}$ Department of Internal Medicine/Nephrology, Maastricht University Medical Center, Maastricht, The Netherlands

Acknowledgements This research was funded by the Dutch Kidney Foundation. The authors thank all (potential) donors who participated in the study. In addition, we thank the following colleagues for their contributions to the study: Desiree Pilzecker, Heinrich Kloke, Ine Dooper, Sabine Hopman, Gerben van den Bosch, Simon van Duin, Irene Vermeulen, Franka van Reekum, Bep Vink, Tanneke Winkel, Elsbeth Berendsen, Hans de Fijter, Ben Gijsbers, Wilma van Zanten, Regien Meijer, Annemarie Roelofs, Ellen Jansen, Dominique Rodenhuis, John Dackus, Elly van Duijnhoven, Michel Knaapen, Carla Schrauwers, Azam Nurmohamed, Marjon van Vliet, Manon Meijer, Gert-Jan Hersbach, Azziz Taabani, Jacintha Jenniskens, Xanne Rooijers, Tessa de Jong-Pulskens, and Janneke Vervelde.

Contributors LW participated in research design, coordination/logistics, performance of the research, data analysis and writing of the paper. HvM participated in research design, coordination/logistics, data analysis and writing of the paper. CWH participated in coordination/logistics, performance of the research and writing of the paper. J-SS participated in performance of the research and writing of the paper. RD participated in performance of the research and writing of the paper. KAMlvdP participated in performance of the research and writing of the paper. JW participated in performance of the research and writing of the paper. HW participated in performance of the research and writing of the paper. PU participated in performance of the research and writing of the paper. AJH participated in research design, coordination/logistics and writing of the paper. LBH participated in research design, coordination/logistics and writing of the paper. AWE participated in research design, coordination/logistics, data analysis and writing of the paper (Guarantor).

Funding This research was sponsored by the Dutch Kidney Foundation (grant number SB136).

\section{Competing interests None declared.}

Patient consent for publication Not applicable.

Ethics approval The Radboud University Medical Center Ethics Committee decided that the study did not fall under the scope of the Medical Research Involving Human Subjects Act. Therefore, approval by an ethics committee was not indicated, because of the absence of any risk for the participants. In all participating centres, the board approved the study. All participants signed informed consent. The clinical and research activities being reported are consistent with the Declaration of Helsinki and the Declaration of Istanbul.

Provenance and peer review Not commissioned; externally peer reviewed.

Data availability statement Data are available upon reasonable request. Data are available upon reasonable request from the corresponding author.

Supplemental material This content has been supplied by the author(s). It has not been vetted by BMJ Publishing Group Limited (BMJ) and may not have been peer-reviewed. Any opinions or recommendations discussed are solely those of the author(s) and are not endorsed by BMJ. BMJ disclaims all liability and responsibility arising from any reliance placed on the content. Where the content includes any translated material, BMJ does not warrant the accuracy and reliability of the translations (including but not limited to local regulations, clinical guidelines, terminology, drug names and drug dosages), and is not responsible for any error and/or omissions arising from translation and adaptation or otherwise.

Open access This is an open access article distributed in accordance with the Creative Commons Attribution Non Commercial (CC BY-NC 4.0) license, which permits others to distribute, remix, adapt, build upon this work non-commercially, and license their derivative works on different terms, provided the original work is properly cited, appropriate credit is given, any changes made indicated, and the use is non-commercial. See: http://creativecommons.org/licenses/by-nc/4.0/.

ORCID iD

Lieke Wirken http://orcid.org/0000-0002-1185-1383

\section{REFERENCES}

1 Port FK, Wolfe RA, Mauger EA. Comparison of survival probabilities for dialysis patients vs cadaveric renal transplant recipients. JAMA 1993;270:1339-43.

2 Schnuelle P, Lorenz D, Trede M, et al. Impact of renal cadaveric transplantation on survival in end-stage renal failure: evidence for reduced mortality risk compared with hemodialysis during long-term follow-up. JASN 1998;9:2135-41.

3 Tonelli M, Wiebe N, Knoll G, et al. Systematic review: kidney transplantation compared with dialysis in clinically relevant outcomes. Am J Transplant 2011;11:2093-109.

4 Chen $\mathrm{K}-\mathrm{H}$, Yeh L-C, Huang $\mathrm{H}-\mathrm{L}$, et al. Factors determining physical and mental quality of life of living kidney donors in Taiwan. Transplant Proc 2016;48:745-8.

5 Clemens KK, Thiessen-Philbrook H, Parikh CR, et al. Psychosocial health of living kidney donors: a systematic review. Am J Transplant 2006;6:2965-77.

6 Fallahzadeh MK, Jafari L, Roozbeh J, et al. Comparison of health status and quality of life of related versus paid unrelated living kidney donors. Am J Transplant 2013;13:3210-4.

7 Gross CR, Messersmith EE, Hong BA, et al. Health-related quality of life in kidney donors from the last five decades: results from the RELIVE study. Am J Transplant 2013;13:2924-34.

8 Mjøen G, Stavem K, Westlie L, et al. Quality of life in kidney donors. Am J Transplant 2011;11:1315-9.

9 Wirken L, van Middendorp $\mathrm{H}$, Hooghof CW, et al. The course and predictors of health-related quality of life in living kidney donors: a systematic review and meta-analysis. Am J Transplant 2015;15:3041-54.

10 Wirken L, van Middendorp H, Hooghof CW, et al. Pre-donation cognitions of potential living organ donors: the development of the donation cognition instrument in potential kidney donors. Nephrol Dial Transpl 2017;32:573-80.

11 Giessing M, Reuter S, Schönberger B, et al. Quality of life of living kidney donors in Germany: a survey with the validated short form-36 and Giessen subjective complaints List-24 questionnaires. Transplantation 2004;78:864-72.

12 Jacobs $\mathrm{C}$, Johnson E, Anderson K, et al. Kidney transplants from living donors: how donation affects family dynamics. Adv Ren Replace Ther 1998;5:89-97.

13 Timmerman L, Laging M, Timman R, et al. The impact of the donors' and recipients' medical complications on living kidney donors' mental health. Transpl Int 2016;29:589-602.

14 Andersen $\mathrm{MH}$, Bruserud F, Mathisen L, et al. Follow-up interviews of 12 living kidney donors one yr after open donor nephrectomy. Clin Transplant 2007;21:702-9.

15 Rodrigue JR, Paek M, Whiting J, et al. Trajectories of perceived benefits in living kidney donors: association with donor characteristics and recipient outcomes. Transplantation 2014:97:762-8

16 Reimer J, Rensing A, Haasen C, et al. The impact of livingrelated kidney transplantation on the donor's life. Transplantation 2006;81:1268-73.

17 Matas AJ, Hays RE, Ibrahim HN. Long-term non-end-stage renal disease risks after living kidney donation. Am J Transplant 2017;17:893-900.

18 Duerinckx N, Timmerman L, Van Gogh J, et al. Predonation psychosocial evaluation of living kidney and liver donor candidates: a systematic literature review. Transpl Int 2014;27:2-18.

19 lacoviello BM, Shenoy A, Hunt J, et al. A prospective study of the reliability and validity of the live donor assessment tool. Psychosomatics 2017;58:519-26.

20 Bahler CD, Sundaram CP. Quality of life following laparoscopic livingdonor nephrectomy. JSLS 2013;17:273-8.

21 Chien $\mathrm{C}-\mathrm{H}$, Wang $\mathrm{H}-\mathrm{H}$, Chiang Y-J, et al. Quality of life after laparoscopic donor nephrectomy. Transplant Proc 2010;42:696-8.

22 de Groot IB, Stiggelbout AM, van der Boog PJM, et al. Reduced quality of life in living kidney donors: association with fatigue, societal participation and pre-donation variables. Transpl Int 2012;25:967-75.

23 Jacobs CL, Gross CR, Messersmith EE, et al. Emotional and financial experiences of kidney donors over the past 50 years: the RELIVE study. CJASN 2015;10:2221-31.

24 Timmerman L, Timman R, Laging M, et al. Predicting mental health after living kidney donation: the importance of psychological factors. Br J Health Psychol 2016;21:533-54.

25 Lennerling A, Lovén C, Dor FJMF, et al. Living organ donation practices in Europe - results from an online survey. Transpl Int 2013;26:145-53.

26 Evers AWM, Zautra A, Thieme K. Stress and resilience in rheumatic diseases: a review and glimpse into the future. Nat Rev Rheumatol 2011;7:409-15.

27 Steptoe A. Invited review. The links between stress and illness. J Psychosom Res 1991;35:633-44.

28 Dutch Transplant Foundation 2016.

29 Hays RD, Sherbourne CD, Mazel RM. The RAND 36-item health survey 1.0. Health Econ 1993;2:217-27. 
30 Vercoulen JHMM, Swanink CMA, Fennis JFM, et al. Dimensional assessment of chronic fatigue syndrome. J Psychosom Res 1994;38:383-92.

31 McCrae RR, Costa PT. The Neo personality inventory manual. Odessa: Psychological Assessment Resources, 1985.

32 Dam-Baggen RKF, Betrokkenheid DIS. EEN zelfbeoordelingslijst Om sociale steun te meten (inventory for social reliance (ISR): a self-report inventory for the measurement of social support). Gedragstherapie 1992;25:27-46.

33 Rodrigue JR, Guenther R, Kaplan B, et al. Measuring the expectations of kidney donors: initial psychometric properties of the living donation expectancies questionnaire. Transplantation 2008;85:1230-4.

34 Boyce P, Parker G. Development of a scale to measure interpersonal sensitivity. Aust N Z J Psychiatry 1989;23:341-51.

35 Gong J, Wang X-qiong, Tong X, et al. Emerging trends of drugresistant HIV-1 among drug-treated patients in former blood donors in Hubei, China: a three-year surveillance from 2004 to 2006. Virol Sin 2011;26:386-92.

36 Dindo D, Demartines N, Clavien PA. Classification of surgical complications: a new proposal with evaluation in a cohort of 6336 patients and results of a survey. Ann Surg 2004;240:205-13.

37 Wirken L, van Middendorp H, Hooghof CW, et al. Psychosocial consequences of living kidney donation: a prospective multicentre study on health-related quality of life, donor-recipient relationships and regret. Nephrol Dial Transpl 2019;34:1045-55.
38 McCollum L, Pincus T. A biopsychosocial model to complement a biomedical model: patient questionnaire data and socioeconomic status usually are more significant than laboratory tests and imaging studies in prognosis of rheumatoid arthritis. Rheum Dis Clin N Am 2009;35:699-712.

39 Palmer D, El Gaafary M, El Miedany Y. Improving patient care: measurement of outcome in rheumatoid arthritis. Brit $J$ Nurs 2007;16:1010-5.

40 Schover LR, Streem SB, Boparai N, et al. The psychosocial impact of donating a kidney: long-term followup from a urology based center. J Urology 1997;157:1596-601.

41 Yoo HJ, Han DJ, Kim SY, et al. Attitudes and psychological characteristics of kidney donors toward organ donation. Transplant Proc 1996;28:1932-3.

42 Dunn WR, Wolf BR, Harrell FE, et al. Baseline predictors of healthrelated quality of life after anterior cruciate ligament reconstruction: a longitudinal analysis of a multicenter cohort at two and six years. J Bone Joint Surg Am 2015;97:551-7.

43 Järvholm K, Karlsson J, Olbers T, et al. Characteristics of adolescents with poor mental health after bariatric surgery. Surg Obes Relat Dis 2016;12:882-90.

44 Dew MA, DiMartini AF, DeVito Dabbs AJ, et al. Preventive intervention for living donor psychosocial outcomes: feasibility and efficacy in a randomized controlled trial. Am J Transplant 2013;13:2672-84. 